\title{
Autogestão dos Recursos Hídricos - Estudo de Caso da Bacia Hidrográfica do Rio Santa Maria-RS
}

\author{
Self-Management of Water Resources - Case Study of River Basin Santa Maria- RS
}

Vagner Neves de Godoy e Rafael Cabral Cruz

Universidade Federal do Pampa, São Gabriel, Brasil

vagnergodoy_@hotmail.com; rafaelcruz@unipampa.edu.br

\begin{abstract}
Resumo
A bacia hidrográfica do rio Santa Maria, localiza-se na fronteira sudoeste do RS e tem uma área de $15.740 \mathrm{~km}^{2}$. A agricultura irrigada é a atividade que possui a maior demanda de água na bacia. O objetivo geral deste artigo é de avaliar o processo de tomada de decisões sobre o conflito de abastecimento público e do abastecimento nas lavouras orizícolas na Bacia Hidrográfica do Rio Santa Maria e avaliar qual o papel da negociação dos conflitos gerados na escassez da água. Propõe-se, também, analisar as discussões e ações efetivas do Comitê em relação aos acordos locais e à autogestão.
\end{abstract}

Palavras-chave: Solução de conflito. Escassez da água. Autogestão dos recursos hídricos.

\begin{abstract}
The basin of the river Santa Maria, located on the southwest border of $R S$ and has an area of 15,740 $\mathrm{km}^{2}$. Irrigated agriculture is the activity that has the highest water demand in the basin. The aim of this article is to evaluate the decision- making process on the conflict of public supply and supply in rice growing crops in the River Basin Santa Maria and evaluate the role of negotiation of conflicts generated in water scarcity. It is proposed also to analyze the discussions and effective actions of the Committee in relation to local agreements and self-management.
\end{abstract}

Keywords: Conflict resolution. Water scarcity. Self-management of water resources. 


\section{Introdução}

A água é um recurso natural essencial para a sobrevivência das espécies habitantes da Terra. Além de indispensável à vida, a água é o suporte da maioria das atividades econômicas e sociais, bem como a geração de energia, abastecimento público, pecuária, agricultura, indústria, e é também considerada solvente universal de substâncias.

Tundisi (2006) destaca que, no amplo contexto social, econômico e ambiental do século XXI, os seguintes principais problemas e processos são as causas principais da "crise da água":

- Intensa urbanização, aumentando a demanda pela água, ampliando a descarga de recursos hídricos contaminados e com grandes demandas de água para abastecimento e desenvolvimento econômico e social (TUCCI, 2008).

- estresse e escassez de água em muitas regiões do planeta em razão das alterações na disponibilidade e aumento de demanda.

- Infra-estrutura pobre e em estado crítico, em muitas áreas urbanas com até 30\% de perdas na rede após o tratamento das águas.

- Problemas de estresse e escassez em razão de mudanças globais com eventos hidrológicos extremos aumentando a vulnerabilidade da população humana e comprometendo a segurança alimentar (chuvas intensas e período intensos de seca).

- Problemas na falta de articulação e falta de ações consistentes na governabilidade de recursos hídricos e na sustentabilidade ambiental.
Esse conjunto de problemas apresenta dimensões em âmbito local, regional, continental e planetário contribuindo para:

- aumento e exacerbação das fontes de contaminação.

- a alteração das fontes de recursos hídricos - mananciais - com escassez e diminuição da disponibilidade.

- aumento da vulnerabilidade da população humana em razão de contaminação dificuldade de acesso à água de boa qualidade (potável e tratada).

Esse conjunto de problemas está relacionado à qualidade e quantidade da água, e, em respostas a essas causas, há interferências na saúde humana e saúde pública, com deterioração da qualidade de vida e do desenvolvimento econômico e social. Além de quantitativa, a escassez da água é qualitativa, devido ao lançamento de matérias na água em desacordo com os padrões ambientais estabelecidos por lei. A poluição hídrica é normalmente causada pelo esgoto residencial, efluentes industriais ou de agrotóxicos lançados nos corpos d'água em quantidade maior que a capacidade de resiliência do corpo hídrico.

A demanda mundial para a produção de alimentos aumenta progressivamente a taxas muito altas. Atualmente, na maioria dos países, continentes e regiões a água consumida na agricultura é de cerca de $70 \%$ da disponibilidade total.

Há uma enorme necessidade de redução desse uso com a introdução de tecnologias adequadas, eliminação dos desperdícios e introdução de reuso e reciclagem. Os usos da água 
incluem uma excessiva utilização para irrigação a partir de águas subterrâneas. De acordo com Llamas \& Martinez Santos (2006), o uso intensivo de água subterrânea para a agricultura em países e regiões áridas e semi-áridas vem provocando drástica diminuição no volume dos aqüíferos, aumento nos custos da extração de água $\left(0,01 \mathrm{U} \$ / \mathrm{m}^{3}\right.$ ou até 0,2 $\mathrm{U} \$ / \mathrm{m}^{3}$ ) e aumento no custo de irrigação por hectare (oscilando entre U\$20 a U\$1.000 por hectare, dependendo da qualidade do bombeamento). O investimento em produção de alimentos mais rentáveis - cash crops - significa maior investimento e usos mais intensivos de água na agricultura. A degradação da qualidade da água superficial e subterrânea é outro componente relevante dos usos da água na agricultura, e essa degradação deve ser quantificada. A eutrofização de lagos, represas e rios é uma das consequências dos usos excessivos de fertilizantes na agricultura, os quais, combinados com alterações de drenagem, podem aumentar consideravelmente e com rapidez os índices de estado trófico, incluindo as águas subterrâneas. A avaliação da água virtual (utilizada na agricultura), desenvolvimento de tecnologias para eliminar desperdícios e melhorar o desempenho na irrigação, introduzir reuso de água na agricultura, são algumas das soluções urgentes nessa área.

O grau em que o desenvolvimento dos recursos hídricos contribui para a produtividade econômica e o bem estar social nem sempre é avaliado, embora todas as atividades econômicas e sociais dependam muito do suprimento e da qualidade da água. À medida que as populações e as atividades econômicas crescem, muitos países estão atingindo rapidamente condições de escassez de água ou se defrontando com os limites para o desenvolvimento econômico (BARROS e AMIN, 2008).

As demandas por água estão aumentando rapidamente, com 70 a $80 \%$ exigidas para a irrigação e menos de $20 \%$ para a indústria e apenas $6 \%$ para consumo doméstico. Através destes dados há uma grande necessidade de realizar planos para a utilização, proteção, conservação e manejo sustentável e racional de recursos hídricos baseados nas necessidades e prioridades da comunidade, dentro do desenvolvimento econômico viável, implementando projetos e programas que sejam economicamente eficientes e adequados.

Com isso os Estados, municípios e comitês de bacias devem estabelecer estruturas de políticas e prioridades adequadas; estabelecer e fortalecer a capacidade institucional, incluindo disposições legislativas e reguladoras, necessária para assegurar a avaliação adequada de seus recursos hídricos e a previsão de enchentes e secas.

A bacia hidrográfica possibilita integrar ações de pesquisa e gerenciamento em uma unidade física bem estabelecida e que pode agregar atividades multi e interdisciplinares (TUNDISI, 2006). A bacia hidrográfica é uma unidade física com fronteiras delimitadas, podendo estender-se por várias escalas espaciais, desde pequenas bacias de 100 a $200 \mathrm{~km}^{2}$ até grandes bacias hidrográficas como a Bacia do Prata $(3.000 .000$ km²) (TUNDISI, 2006); é um ecossistema hidrologicamente integrado, com componentes e subsistemas interativos; oferece oportunidade para o 
desenvolvimento de parcerias e a resolução de conflitos; permite que a população local participe do processo de decisão; estimula a participação da população e a educação ambiental e sanitária; garante visão sistêmica adequada para o treinamento em gerenciamento de recursos hídricos e para o controle da eutrofização (gerentes, tomadores de decisão e técnicos); é uma forma racional de organização do banco de dados; garante alternativas para o uso dos mananciais e de seus recursos; é uma abordagem adequada para proporcionar a elaboração de um banco de dados sobre componentes biogeofísicos, econômicos e sociais; promove a integração institucional necessária para o gerenciamento do desenvolvimento sustentável (TUNDISI, 2006).

Conforme Viana (2008), a autogestão é uma relação social específica, uma relação de produção, o que significaria relações de trabalho e de distribuição. A autogestão é a decisão coletiva dos produtores sobre o processo de produção, isto é, os próprios produtores iriam gerir o processo de produção. A autogestão só pode existir em locais isolados por um curto período de tempo e em confronto com o conjunto da sociedade. Ainda conforme Viana (2008), a democracia é vista como uma forma de reprodução da divisão da sociedade de classes, uma forma de dominação. A democracia é um produto do desenvolvimento das lutas sociais e da ação do Estado. Este, por sua vez, expressa os interesses da classe dominante. Por conseguinte, a democracia é uma das formas como o Estado capitalista se relaciona com as classes sociais e está envolvida no conjunto de relações sociais desta sociedade (Estado, divisão social do trabalho, mercado, classes sociais, capital, etc.).

A autogestão dos recursos hídricos, referente à relação entre a demanda da água para a população local e a demanda para produção de alimentos, envolve decidir coletivamente a gestão dos recursos sanando a falta dos mesmos sem que haja um comprometimento dos setores.

O objetivo do presente artigo é avaliar o processo de tomada de decisões sobre o conflito entre o abastecimento público e o abastecimento de lavouras orizícolas na Bacia Hidrográfica do Rio Santa Maria e avaliar qual o papel da negociação autogestionária dos conflitos gerados na escassez da água.

\section{Comitês de Bacia Hidrográfica}

Os comitês são órgãos colegiados com atribuições normativas, deliberativas e consultivas a serem exercidas na bacia hidrográfica de sua jurisdição (art, 1, § 1ํo, de Resolução 5 de 10 de abril de 2000, do Conselho Nacional dos Recursos Hídricos; CNRH, 2000).

Conforme o Art. 37 da lei 9433/97 (BRASIL, 1997), os Comitês de Bacia Hidrográfica terão como área de atuação: a totalidade de uma bacia hidrográfica; sub-bacia hidrográfica de tributário do curso de água principal da bacia, ou de tributário desse tributário; ou grupo de bacias ou sub-bacias hidrográficas contíguas. A instituição de Comitês de Bacia Hidrográfica em rios de domínio da União deve ser efetivada por ato do Presidente da República. Ainda na lei 9433/97, no art. 38: 
Compete aos Comitês de Bacia Hidrográfica, no âmbito de sua área de atuação: promover o debate das questões relacionadas a recursos hídricos e articular a atuação das entidades intervenientes; arbitrar, em primeira instância administrativa, os conflitos relacionados aos recursos hídricos; aprovar o Plano de Recursos Hídricos da bacia; acompanhar a execução do Plano de Recursos Hídricos da bacia e sugerir as providências necessárias ao cumprimento de suas metas; propor ao Conselho Nacional e aos Conselhos Estaduais de Recursos Hídricos as acumulações, derivações, captações e lançamentos de pouca expressão, para efeito de isenção da obrigatoriedade de outorga de direitos de uso de recursos hídricos, de acordo com os domínios destes; estabelecer os mecanismos de cobrança pelo uso de recursos hídricos e sugerir os valores a serem cobrados; estabelecer critérios e promover o rateio de custo das obras de uso múltiplo, de interesse comum ou coletivo (BRASIL, 1997).

Segundo a lei 10.350/1994 (RIO GRANDE DO SUL, 1995), art. 12o, "em cada bacia hidrográfica será instituído um Comitê de Gerenciamento de Bacia Hidrográfica, ao qual caberá a coordenação programática das atividades dos agentes públicos e privados, relacionados aos recursos hídricos, compatibilizando, no âmbito espacial da sua respectiva bacia, as metas do Plano Estadual de Recursos Hídricos com a crescente melhoria da qualidade dos corpos de água". Ainda nesta lei, no artigo 13o, diz-se que cada Comitê será constituído por:

I - representantes dos usuários da água, cujo peso de representação devem refletir, tanto quanto possível, sua importância econômica na região e o seu impacto sobre os corpos de água;

II - representantes da população da bacia, seja diretamente provenientes dos poderes legislativos municipais ou estaduais, seja por indicação de organizações e entidades da sociedade civil;

III - representantes dos diversos órgãos da administração direta federal e estadual, atuantes na região e que estejam relacionados com os recursos hídricos, executados aqueles que detém competência relacionadas à outorga do uso da água ou licenciamento de atividades potencialmente poluidoras (RIO GRANDE DO SUL, 1995).

\section{Instrumentos de gestão dos recursos}

\section{hídricos}

Através da lei oํ 9433/97 (BRASIL, 1997), os instrumentos de gestão dos recursos hídricos a serem seguidos são os seguintes: Plano de recursos hídricos, enquadramento dos corpos de água em classes segundo os usos predominantes, outorga de uso dos recursos hídricos, cobrança, sistema de informações sobre os Recursos Hídricos.

O plano de recursos hídricos é o documento/ plano diretor no qual são dispostas as prioridades de gestão, metas e a real situação de disponibilidade qualitativa e quantitativa dos recursos hídricos, propostas para a criação de áreas sujeitas a restrição de uso, com função de orientar a aplicação dos outros instrumentos (Art.6).

O enquadramento dos corpos de água em classes segundo os usos predominantes define os usos que se deseja realizar destes recursos, assegurando à qualidade das águas a qualidade adequada com os usos mais exigentes a que se destinarem (Art. 9).

A outorga de uso dos recursos hídricos concede o direito de uso da água perante o Estado, considerando o balanço entre a disponibilidade e a demanda.

A cobrança tem como objetivo de reconhecer a água como um bem econômico, incentivando a racionalização do uso dos recursos (Art. 19). Visando aplicar o princípio do poluidor pagador, sendo o valor cobrado obrigatoriamente investido na bacia, de acordo com as prioridades do seu plano. 
O sistema de informações sobre os Recursos Hídricos é um sistema de coleta, tratamento, armazenamento e recuperação de informações sobre recursos hídricos e fatores intervenientes em sua gestão.

É muito importante observar volume de água outorgada, pois não deve comprometer a vazão de diluição definida para a manutenção dos parâmetros da qualidade do enquadramento existente no local.

\section{Gestão dos recursos hídricos do Estado}

\section{do Rio Grande do Sul}

A Secretaria Estadual dos Recursos Hídricos tem a Secretaria Estadual do Meio Ambiente (SEMA) como órgão gestor do sistema, o
Departamento de Recursos Hídricos do Rio Grande do Sul (DRH) como órgão gestor dos recursos hídricos, agindo como administrador direto e o Conselho de Recursos Hídricos (CRH) como órgão que regulamenta os instrumentos de gestão de recursos hídricos e de conflitos pelo uso da água, caso não seja decidido em âmbito regional pelo comitê de bacia (DRH, 2010).

Os comitês e o Conselho Estadual de Recursos Hídricos são responsáveis pela gestão participativa e descentralizada, com função deliberativa e poderes para decidir sobre as questões da Política de Recursos Hídricos, com o dever de reunir os usuários da água, poder público, representantes políticos e entidades atuantes nas bacias.

Tabela 1 - Situação dos planos de bacias no Estado do Rio Grande do Sul.

\begin{tabular}{|c|c|c|}
\hline Bacia Hidrográfica & Estágio do plano de bacia & Ano \\
\hline Rio Gravataí & \multirow{5}{*}{ Elaborado (Fases A, B e C) } & 2012 \\
\hline Rio dos Sinos & & 2014 \\
\hline Lago Guaíba & & 2014 \\
\hline Rio Caí & & 2015 \\
\hline Baixo Jacuí & & 2015 \\
\hline Rio Pardo & \multirow{7}{*}{$1^{\mathrm{a}}$ Etapa elaborada (Fases A e B) } & 2005 \\
\hline Rio Ijuí & & 2012 \\
\hline Rio Ibicuí & & 2011 \\
\hline Alto Jacuí & & 2012 \\
\hline Taquari-Antas & & 2012 \\
\hline Rio Passo Fundo & & 2011 \\
\hline Rios Turvo-Santa Rosa-Santo Cristo & & 2012 \\
\hline Rio Tramandaí & $\begin{array}{l}\text { 1ª Etapa concluída em 2005; em contratação } \\
\text { Fase C }\end{array}$ & 2016 (previsão) \\
\hline Rio Santa Maria & \multirow{3}{*}{ Em elaboração (fases A, B e C) } & $\begin{array}{l}\text { Abril/2016 } \\
\text { (previsão) }\end{array}$ \\
\hline Rio Camaquã & & 2016 (previsão) \\
\hline Rios Apuaê-Inhandava & & 2017 (previsão) \\
\hline
\end{tabular}


A Secretaria Estadual dos Recursos Hídricos tem ainda, como órgão técnico a Fundação Estadual de Proteção Ambiental Henrique Luis Roessler (FEPAM), responsável pela operacionalização da outorga pelo uso da água para a diluição de efluentes e determinação do enquadramento.

Em relação à implementação de instrumentos de planejamento e gestão, os planos de bacias e a cobrança pelo uso da água não foram implantados em todo o Estado. Segundo SEMA (2016), das 25 bacias em que se divide o Rio Grande do Sul, somente existem planos completos (Fases A, B e C) para cinco bacias do estado (Tabela 1).

Por sua vez, a outorga teve seu inicio de implementação em meados de 1999, pelo
Departamento de Recursos Hídricos, sendo em caráter precário, uma vez que a rede de monitoramento tanto da oferta quanto da demanda da água não esta operacionalizada de modo a atender critérios hidrológicos que a tornem mais confiáveis.

\section{Materiais e Métodos}

\subsection{Localização e caracterização da bacia do} rio Santa Maria

A Bacia Hidrográfica do Rio Santa Maria localiza-se na fronteira sudoeste do Estado do Rio Grande do Sul, onde faz parte da região denominada Metade Sul do Estado (Figura 1).

\section{Mapa de Situação e Localização da Bacia do Rio Santa Maria, RS, Brasil.}

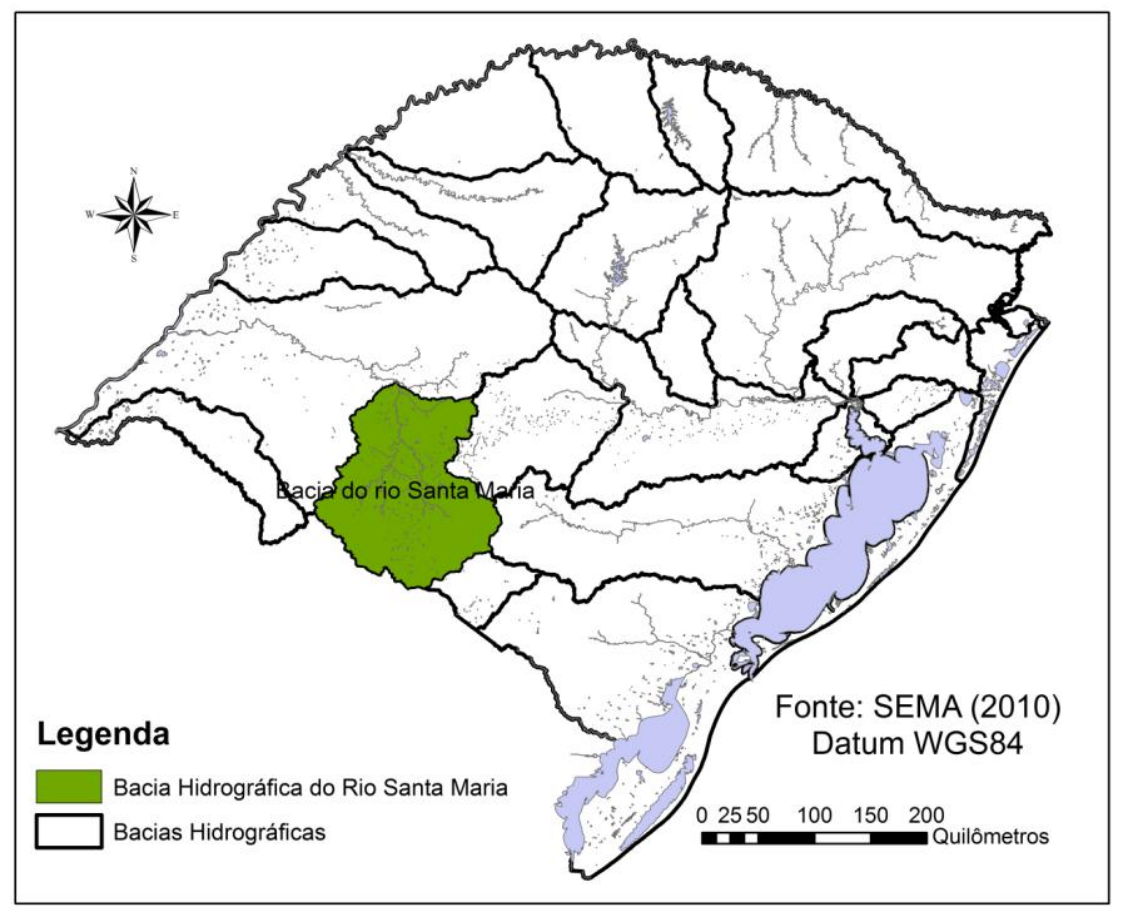

Figura 1 - Mapa de situação e localização da bacia hidrográfica do rio Santa Maria, RS, Brasil 
A Bacia tem uma área de $15.740 \mathrm{Km}^{2}$ abrangendo o município de Cacequi, Dom Pedrito, Rosário do Sul, São Gabriel, Lavras do Sul e Santana do Livramento. O rio Santa Maria tem sua origem no município de Dom Pedrito e a Foz em Cacequi, onde conflui com o rio Ibicuí-Mirim e forma o rio Ibicuí. Este por sua vez afluente do rio Uruguai. Estes municípios somam 241.858 habitantes, entretanto, a população que reside dentro da bacia é aproximadamente de 184.000 (destes 15\% em áreas rurais), uma vez que as sedes dos municípios de São Gabriel e Lavras do Sul situam-se fora dos limites da bacia (IBGE, 2010).

A atividade econômica da região caracteriza-se pela atividade agropecuária, apresentando paisagens típicas da fronteira gaúcha, onde a pecuária extensiva se mescla com a orizicultura, em campos entremeados com várzeas ocupadas por rotação de pastagem natural e lavoura de arroz. Ainda destaca-se a sojicultura, vitivinicultura e citricultura em processo acelerado de implantação, extração de areia e uso recreativo das águas (DULAC, 2013).

\subsection{Pesquisa documental}

Para a realização deste artigo foram pesquisadas atas das reuniões do Comitê de Gerenciamento da Bacia do Rio Santa Maria, disponibilizadas em meio digital pela secretaria executiva do Comitê e sítio do Comitê (CBHSM, 2014), sendo da ata $n^{-} 112$ até a ata $n^{-0} 133$ e as Resoluções no 15/2005 (CRH, 2005); Resolução n⿳31/2007 (CRH, 2007) e a Resolução nº 96/2011 (CRH, 2011).

O procedimento analítico envolveu a elaboração de três tabelas que foram adaptadas do banco de dados proposto por Dulac (2013). Cada uma das tabelas foi construída conforme exemplo apresentado na Tabela 2 em planilha eletrônica Excel. As manifestações, entendidas como um fragmento de discurso que apresenta uma ou mais ideias que foram classificadas, de acordo com a interpretação dos autores, em: 1) autogestão, 2) abastecimento público e 3) acordos locais. Cada vez que os autores localizaram uma manifestação que envolvia uma destas categorias de ideias, criavam um registro na tabela respectiva. Assim, não foram analisadas todas as ideias, como efetuado por Dulac (2013), mas somente os fragmentos de discurso que versaram sobre as ideias relativas ao objetivo deste estudo.

A sistematização envolveu a organização temporal das manifestações e a interpretação, com base na identificação do conflito entre abastecimento público e irrigação, análise das propostas e encaminhamentos e dos produtos resultantes (decisões do Comitê). 
Tabela 2 - Modelo de tabela para organização das manifestações presentes nas Atas das reuniões do Comitê de Gerenciamento da Bacia do Rio Santa Maria, RS, Brasil

\begin{tabular}{|c|c|c|c|c|c|c|}
\hline Ano & $\begin{array}{c}\text { Número } \\
\text { da ata }\end{array}$ & Nome & Entidade & Grupo & Categoria & Manifestação \\
\hline 2011 & 128 & E.C. & $\begin{array}{c}\text { Prefeitura } \\
\text { Municipal de } \\
\text { Dom } \\
\text { Pedrito/Sindicat } \\
\text { o Rural de Dom } \\
\text { Pedrito }\end{array}$ & Usuários & $\begin{array}{c}\text { DRENAGEM } \\
\text { /PRODUÇÃ } \\
\text { O RURAL }\end{array}$ & 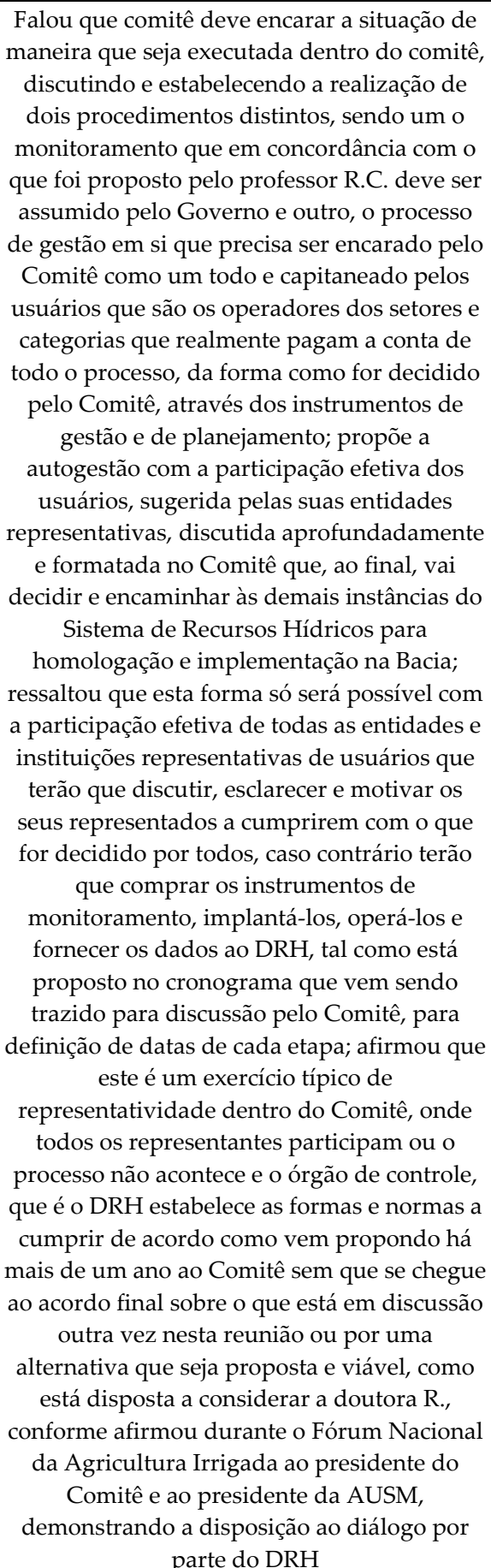 \\
\hline
\end{tabular}

Fonte: adaptado de Dulac (2013). 


\section{Resultados e Discussões}

No âmbito dos discursos do Comitê da Bacia Hidrográfica do Rio Santa Maria há um conhecimento de que a falta de água é um grande problema na bacia, visto que nas estações mais severas, como o verão, há uma grande demanda de água, tanto das plantações de arroz quanto da população residente na bacia. De acordo com a Ata 117, a CORSAN (Companhia Riograndense de Saneamento) de Dom Pedrito teve um dos maiores problemas de abastecimento na época, um pouco pela falta água, mas grande parte pela má gestão. Com isso, foi aprovada a proposta de que o processo de autogestão fosse implementado, baseado no Estudo da Universidade Federal de Santa Maria, aprovado pelo Comitê em 2004, considerando a situação existente naquela época, segundo a qual, em anos secos há necessidade de racionamento de água, mesmo com vazão remanescente ou ecológica zero (Ata 117). Observase que a decisão foi tomada, no âmbito do Comitê, em função da inexistência de implementação dos instrumentos de gestão. Na época, os representantes no Comitê deliberaram no vácuo causado pela inexistência de uma outorga plena, que envolvesse a determinação do regime de vazões remanescentes para cada trecho de rio, respeitando-se as prioridades determinadas pela lei das águas.

Ainda na mesma reunião, o comitê decidiu sobre a inclusão dos irrigantes que ficaram de fora dos processos anteriores, baseado na necessidade de que os acordos locais e o processo de autogestão só funcionariam com a concordância de todos os envolvidos e dependentes, sendo solicitada a verificação de quais outras condições ou acordos seriam necessários, considerando que, em alguns momentos durante este processo, e especificamente nos períodos de irrigação, poderia haver vazão nula em algum, ou alguns, pontos da Bacia como estava registrado no Estudo da UFSM aprovado pelo Comitê e que é a base do processo que seria colocado em prática e que deveria legitimar a transição desta situação para a situação de outorgas definitivas, depois de novos estudos, balanços hídricos e monitoramentos que o Comitê estava propondo, começando por um Simpósio das Águas da Bacia do rio Santa Maria, cuja proposta também seria levada ao DRH, com o objetivo geral de estabelecer critérios para a outorga dos direitos de uso da água, para o enquadramento dos corpos d'água e para a cobrança pelo uso da água, de forma integrada. Sobre a ideia geral do projeto da UFSM, Na Ata 119, fala sobre a criação de critérios para a gestão dos $\mathrm{RH}$ a partir da resposta de três perguntas: Existe água disponível no manancial escolhido pelo usuário, para atender o uso? A água disponível possui qualidade compatível com o uso pretendido?(Ata 119).

Com base nos dados relatados nas reuniões do comitê, notou-se que havia uma grande preocupação por parte dos membros em relação à outorga das águas. Foi feito um acordo com os produtores e o poder público que quando a água do rio Santa Maria atingisse um certo nível, os produtores seriam obrigados a suspender a retirada da água, priorizando o abastecimento público. À medida que o nível do rio fosse aumentando, os produtores retornariam às atividades (CRH, 2005). 
Com isso, os membros do comitê realizaram uma reavaliação da Resolução $n^{-1}$ 15/2005, que aprova o enquadramento das águas da bacia do rio Santa Maria e determina, no seu artigo segundo, que esta resolução deve ser encaminhada para o DRH/SEMA e para a FEPAM para que seja considerada na emissão das outorgas e no licenciamento ambiental.

$\mathrm{Na}$ ata 121 foi discutido que, até aquele momento, somente existia a Resolução no 31/2007, como amparo legal para regular os níveis de monitoramento da régua na Bacia. Manifestou-se que este monitoramento era modelo no Estado do Rio Grande do Sul. O monitoramento, realizado através de uma comissão de representantes das entidades, vinha funcionando com efetividade, regulando os conflitos entre abastecimento público e orizicultura irrigada, tanto que não havia sido necessário, até a data, a intervenção do Estado e do Ministério Público. No entanto, a prática do monitoramento estava demonstrando que as regras deviam ser aperfeiçoadas, atualizando os níveis críticos e as regras de captação. O representante da AUSM (Associação de usuários da água da Bacia do Rio Santa Maria) afirmou que, no que se trata desta resolução ainda antiga, eram necessárias alterações em alguns itens que não se aplicavam, pelo regime dos rios da bacia, resultando em perda de tempo, por serem medidas inócuas, como por exemplo, alternar dias para puxar água do Rio Santa Maria. O mesmo representante afirmou que estava constrangido, como representante do comitê, em função de que faltavam poucos dias para completar um ano desde a primeira vez que foi feita a proposta de um Sistema de Autogestão por Acordos Locais. Neste período, o assunto nunca evoluiu dentro do Comitê, no sentido de ser colocado em prática pelas entidades representantes de usuários de água da Bacia, nos moldes do sistema que funcionava rigorosamente dentro do padrão desejável para o controle da água necessária ao abastecimento público da cidade de Dom Pedrito. Ainda, conforme o representante da AUSM, "não existindo um bom sistema de Outorgas que funcione através de um processo de Autogestão, não vai funcionar nenhum sistema de controle de uso das águas, inviabilizando ou no mínimo prejudicando a operação e administração das barragens. Com isso, a comissão formada para atuar no monitoramento e viabilização do abastecimento da cidade de Dom Pedrito teve seus resultados esperados comprovados, testando uma pequena parte na Bacia do rio Santa Maria, sendo este o Modelo que deve funcionar para toda a Bacia do Rio Santa Maria" (ATA 121). Na reunião subsequente, discutiu-se que as obras oferecidas e a serem executadas (barragens do Jaguari e Taquarembó) deveriam funcionar dentro de um sistema controlado de outorgas, de acordo com os procedimentos de autogestão adotados na época, que possibilitariam a inserção de todos os sistemas de acumulação e distribuição de água a serem construídos, dentro de um sistema maior, funcionando de acordo com a Legislação de Recursos Hídricos, sendo de responsabilidade do comitê deliberar nesse interesse, pela adoção ou não do processo de autogestão. A definição e operacionalização deste trabalho faria com que ele 
efetivamente funcionasse e o Comitê cumprisse com sua função no processo de Gestão dos Recursos Hídricos, o que é a única forma de habilitar a Bacia a receber outros investimentos em acumulação de água (Ata 122).

$\mathrm{Na}$ Ata 125, encontra-se a discussão referente às vantagens de serem adotados os traçados dos canais de irrigação para as barragens do Taquarembó e Jaguari elaborados pela AUSM em parceria com o Comitê, quando comparados com os traçados de canais propostos nos estudos presentes na proposta licitada pelo Governo do Estado. Os traçados do Governo do Estado permitiriam o aumento de uma área potencial irrigável de dez mil hectares abaixo do canal principal do Taquarembó e oitocentos hectares do canal do Jaguari, canal este que é bastante critico em termos de avaliação de viabilidade. Já a proposta elaborada pela AUSM permitiria aumentar para cento e dezesseis mil hectares irrigáveis por gravidade, a partir dos novos canais propostos, no trecho entre as rodovias BR-290 e BR-293, tendo estes perímetros de irrigação a possibilidade de serem utilizados por múltiplos usos, além do abastecimento de cidade de Dom Pedrito. Com isso, a viabilidade destas obras e a sustentabilidade passariam necessariamente pelo sistema, tendo que estar vinculados ao sistema de gestão de bacias, processo que era almejado pelo Comitê. Com este sistema proposto pela AUSM, não haveria mais captação direta no Rio Santa Maria, reduzir-se-ia a pressão de captação no terço final do rio, o que resultaria na redução dos impactos ambientais resultantes das inúmeras captações diretas localizadas às margens do rio Santa Maria (Ata 125).

Neste caso dos canais, mais uma vez observa-se a iniciativa dos representantes do Comitê para resolução de conflitos causados pela ineficácia do Governo.

Posteriormente, foi relatada a questão dos níveis críticos para o abastecimento público, onde foi analisada uma possível alteração da Portaria 31/2007. Discutiu-se que, nas atuais condições climáticas, nos anos em que o fenômeno La Niña predominava, eram reduzidas as precipitações o que exigia que o Comitê tomasse providências e antecipasse os conflitos como forma de prevenção. Em Dom Pedrito existia uma comissão, que monitorava a régua instalada no lagoão da CORSAN e, quando as águas chegavam aos níveis de alerta e críticos, a comissão tomava imediatamente as providências, conforme determinava a resolução do CRH. Manifestou-se que a portaria deveria passar por uma revisão nos seus artigos, partindo para uma readequação, no caráter de prevenção. Foram dadas sugestões nos

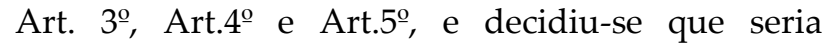
elaborada uma minuta com as correções e enviada aos membros do Comitê, para ser, posteriormente, encaminhada para o $\mathrm{CRH}$. As alterações pertinentes aos artigos que seriam modificados na Portaria 31/2007 são relacionadas ao que dizem os seguintes artigos (CRH, 2007):

Art. 3o Estabelecendo que a captação de água para irrigação seja intermitente-2 (dois) dias com bombeamento e 3 (três) dias sem bombeamento - a partir da zero hora do dia subsequente aquele em que o nível do rio Santa Maria atingir o Nível de Alerta de 2,60m (dois metros e sessenta centímetros)"; onde será definido as correções na intermitência. 
Art. $4^{\circ}$ Estabelecendo que se o nível da água do Rio Santa Maria atingir 2,25m (dois metros e vinte e cinco centímetros) medido na régua instalada na captação da CORSAN situada em Dom Pedrito, a captação de água para irrigação será imediatamente suspensa.

Art. $5^{\circ}$ Estabelecendo que para as captações localizadas no interior da área do remanso (lagoão), o bombeamento continuado somente será permitido enquanto o nível do Santa Maria, medido na captação da CORSAN em Dom Pedrito, se mantiver acima de $3,20 \mathrm{~m}$ (três metros e vinte centímetros).

Na Ata 127, manifestou-se que a Resolução no 31/2007, que rege sobre os níveis críticos para o abastecimento público no Rio Santa Maria e, também, estabelece os critérios de retirada de água do rio Santa Maria, estava vencida desde 15 de março de 2007. Relatou-se que na reunião da Comissão Permanente de Assessoramento (CPA) foram propostas modificações para esta resolução. A primeira delas foi modificar o Art. 2o estabelece o nível da cota de $(2,60 \mathrm{~m})$, onde a cota real é representada de forma diferente, $(122,60 \mathrm{~m})$ mantendo o mesmo nível identificado, a ser acionado o nível de alerta. Também se manifestou que, junto com a nova resolução, seria preciso homologar uma comissão local de controle, que informaria o Departamento de Recursos Hídricos quando se atingisse o nível crítico do lagoão. Foi apresentada a proposta de que a Comissão seria formada pela CORSAN, Prefeitura, Sindicato Rural, Associação dos Agricultores, Associação dos Agrônomos, Comitê e Associação dos Usuários da Água. Foi proposto que o Art. $3^{\circ}$, que fala sobre a intermitência, seria excluído, porque não funcionava na prática. $\mathrm{O}$ controle seria realizado com a condição de quando se atingisse o nível de aleta seria alertado o produtor sobre situação de controle, e quando atingisse o nível crítico $(122,25 \mathrm{~m})$, teria que ser realizada a paralisação de forma imediata. Também se propôs a inclusão na resolução a questão da captação no lagoão da CORSAN, que, conforme as portarias de outorga no período de 30 de outubro a 30 de março, as captações localizadas no lagoão não teriam outorga, ou seja, não se permitiria o uso do lagoão nesse período. Por fim, foi proposto acrescentar, no Art. 5o, que somente seria permitido retomar a captação quando se atingisse a cota $122,90 \mathrm{~m}$. Também se definiu a necessidade de que fosse criada uma Comissão de Acompanhamento para a cidade de Rosário do Sul, onde o acordo já havia se implantado de fato, mas não havia sido homologado pelo CRH.

Na sequência, os acordos resultantes foram encaminhados para o $\mathrm{CRH}$, que homologou o processo de negociação, que foi oficializado através da Resolução 96/2011 (CRH, 2011), onde foram definidas as responsabilidades:

\footnotetext{
Art." 1ํ- Aprovar o Acordo construído no âmbito do Comitê Santa Maria, mediante o qual ficam estabelecidos os condicionantes do bombeamento de água para irrigação, a partir dos cursos de água superficiais situados à montante da captação de água para o abastecimento público da sede do município de Dom Pedrito e da sede do município de Rosário do Sul pelo rio Ibicuí da Armada.

Art. $2^{\circ} \mathrm{O}$ monitoramento do regramento desta Resolução se dará por uma comissão local, formada pela Prefeitura Municipal, CORSAN, Comitê de Gerenciamento da Bacia Hidrográfica do rio Santa Maria, Sindicato Rural, Associação dos Usuários da Água da Bacia Hidrográfica do rio Santa Maria, Associação dos Agricultores (no município de Dom Pedrito), Associação dos Arrozeiros (no município de Rosário do Sul) e Associação dos Engenheiros Agrônomos.

Art. 3o - Estabelecer que se o nível da água do rio Santa Maria e no rio Ibicuí da Armada atingir os níveis críticos: em Dom Pedrito na cota 122,25 m (cento e vinte e dois metros e vinte e cinco centímetros); em Rosário do Sul no rio Ibicuí da Armada na cota 87,14m (oitenta e sete metros e quatorze centímetros), medido na régua instalada nas captações da CORSAN, as captações de água para irrigação a montante da captação da CORSAN serão comunicadas ao DRH pelo Comitê e imediatamente suspensas; Parágrafo Único - Atingido os níveis: em
} 
Dom Pedrito da cota 122,25m (cento e vinte e dois metros e vinte e cinco centímetros); em Rosário do Sul da cota 87,14m (oitenta e sete metros e quatorze centímetros), a comissão local de cada município informará ao Comitê e este requererá formalmente ao Departamento de Recursos Hídricos (DRH) a suspensão temporária das Portarias de Outorgas a montante de Dom Pedrito e/ou de Rosário do Sul no rio Ibicuí da Armada, a partir do dia do comunicado pelo Comitê ao DRH.

Art. $4^{\mathrm{o}}$ - A retomada dos regimes de bombeamento estabelecidos no Art. 2º Parágrafo único, somente serão autorizados em Dom Pedrito quando o nível de água atingir a cota de $122,90 \mathrm{~m}$ (cento e vinte e dois metros e noventa centímetros); em Rosário do Sul, quando o nível atingir a cota $88,00 \mathrm{~m}$ (oitenta e oito metros), mediante comunicado da Comissão local de monitoramento ao Comitê e este imediatamente comunica ao Departamento de Recursos Hídricos. Parágrafo Único: A partir do comunicado formal do Comitê ao Departamento de Recursos Hídricos (DRH), das Outorgas suspensas, estas ficam liberadas para o uso.

Art. 5o - A CORSAN informará diariamente o nível do rio Santa Maria ao Departamento de Recursos Hídricos e à Secretaria Executiva do Comitê Santa Maria, a quem competirá repassar a informação aos representantes das Entidades-membro".

O Comitê possui um grande poder de decisão no que diz respeito a problemas locais. A Figura 2 demonstra que quando há alguma anormalidade no sistema da bacia que afete a população, o assunto torna-se muito frequente, e que quando este problema é solucionado, o tema acaba desaparecendo das atas. Estes resultados confirmam e detalham o padrão já identificado por Dulac e Cruz (2015), que identificaram um aumento das manifestações autogestionárias no período entre as Atas 115 e 133. Os autores também demonstraram que este processo ocorreu simultaneamente com a presença de uma grande incerteza quanto à oferta de água e com uma baixa frequência de ideias relativas aos instrumentos de enquadramento e cobrança e quanto a agência de bacia. Isto se deve ao fato de que ainda não se encontrava em pauta a elaboração do Plano de Bacia, que está previsto para encerrar em abril de 2016 e que teve sua dinâmica fortemente condicionada pela cultura autogestionária que se desenvolveu como processo de negociação dos conflitos entre abastecimento público e irrigação. Profill Engenharia e Ambiente Ltda. (2014), no primeiro relatório técnico referente à elaboração do Plano de Bacia do rio Santa Maria, observa:

\begin{abstract}
Um ponto a ser observado é uma característica de autogestão no âmbito da administração das águas na Bacia a qual tem sido ampliado ao longo do tempo. Tal processo teve início em 2005, com os acordos locais entre irrigação e abastecimento.

A partir de 2008 o Comitê torna-se um articulador do cadastro de usuários para emissão de outorgas. No ano de 2012, (com discussões iniciadas em 2010), aprova uma comissão para negociar com o DRH e apresenta uma proposta, articulada pela categoria da produção rural, de outorgas coletivas por sub-bacia. Também em 2010, articula-se junto a AUSM, pleiteando que referida Associação administre e opere a infraestrutura das barragens de usos múltiplos, no contexto da autogestão pelos próprios usuários. O parecer técnico da CPA $\mathrm{n}^{\mathbf{0}}$ 01/2013 (o qual pode ser observado em AUSM, 2014) contém 25 pontos de análise desta questão.
\end{abstract}

A trajetória do processo de construção da solução autogestionária para o conflito entre abastecimento público e irrigação também mostra que as diversas escalas decisórias que constituem o sistema de gestão de recursos hídricos se constroem em ritmos que nem sempre são adequados à resolução dos conflitos. Ou seja, foi no vácuo da atuação das instituições responsáveis em nível estadual que a comunidade, a partir do Comitê de Bacia, organizou as instituições locais, juntamente com os usuários das águas, para construir uma solução viável de ser implementada no tempo hábil de resolução do conflito. Davis (2007), ao analisar a implantação dos sistemas de gestão de recursos hídricos sob a estrutura conceitual da Gestão Integrada de Recursos Hídricos (GIRH), concluiu que o lento avanço da GIRH, evidenciado através da visão histórica de gestão setorial, da limitada 
participação e de critérios restritivos, resulta de resultados sub-ótimos que muitas vezes causam impactos irreversíveis, como sobre populações indígenas e hábitats de espécies silvestres. Segundo o autor, o ritmo com que os mecanismos mais amplos da GIRH se traduzem em aperfeiçoamentos institucionais e normas legais condiciona a viabilidade da gestão sustentável dos recursos hídricos. Deste modo, embora se reconheça que o alcance da autogestão pode ser limitado (Viana, 2008), as iniciativas autogestinárias acabam por tensionar pelo aperfeiçoamento institucional e pelo empoderamento da população.

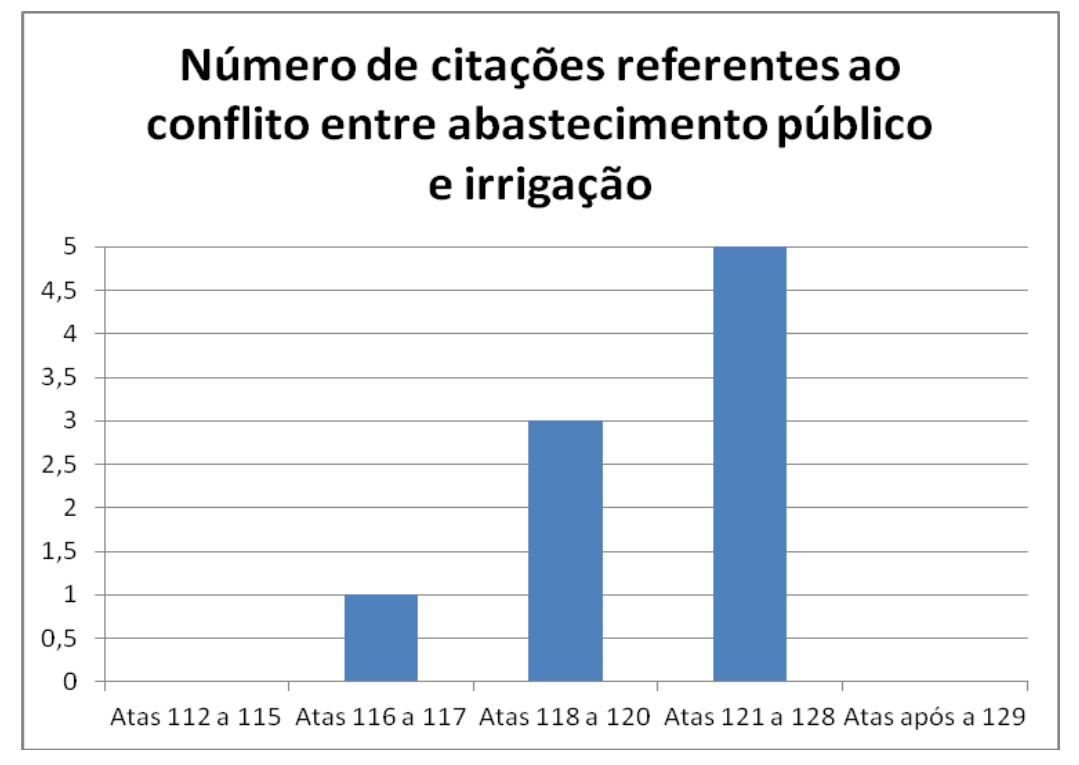

Figura 2 - Número de citações nas Atas 112 a 133 do Comitê de Gerenciamento da Bacia do Rio Santa Maria referentes ao conflito entre abastecimento público e irrigação

\section{Conclusões}

Com base no material documental, verificase que o processo de negociação entre as partes interessadas foi obtido com sucesso, pois a autogestão das águas foi implementada pelo Comitê.

É importante destacar que, no período de análise (fevereiro/2010, ata nำ112 à maio/2012, ata nº133), todos os instrumentos de gestão e planejamento, dispostos na Lei no 10.350/1994, fizeram parte das discussões do Comitê da Bacia Hidrográfica do Rio Santa Maria.

A evolução das ideias de gerenciamento dos Recursos Hídricos e autogestão dos mesmos é vista como um grande avanço na sociedade, que buscou seus próprios mecanismos de negociação em resposta à ausência da implementação plena dos instrumentos de gestão dos recursos hídricos.

Cabe ressaltar que o Comitê age incansavelmente para a resolução destes problemas. Pode-se observar que, no caso do conflito entre abastecimento público e irrigação, o Comitê obteve 
êxito quanto a autogestão da água, tendo negociado efetivamente critérios para a retirada da água do rio Santa Maria, priorizando o abastecimento público das cidades, mas sem deixar de atender os produtores daquela região. A autogestão da água foi implementada de modo eficaz, mesmo que precário, pois não existem estudos que estabeleçam o regime de vazões remanescentes para o rio Santa Maria de forma consistente e que permitissem que o instrumento de outorga, implementado de forma plena, regulasse este conflito. A sociedade ocupou o vácuo deixado pelo Estado, que, na sequência, reconheceu a sua iniciativa e homologou as negociações através das Resoluções 31/2007 e 96/2011.

Este processo de autogestão, portanto, pode servir de exemplo para outros comitês, contribuindo para uma melhor gestão dos recursos hídricos, preservando-os e usando-os de forma racional e ecologicamente viável.

\section{Agradecimentos}

Agradecemos aos professores Jefferson Marçal da Rocha e André Carlos Cruz Copetti pela revisão criteriosa e sugestões e ao Gestor Ambiental Vinícius Ferreira Dulac pelas contribuições para montagem do banco de dados.

\section{Referências}

ANA. Agência Nacional de Águas (2013). Conjuntura Recursos Hídricos no Brasil 2013. < http://arquivos.ana.gov.br/institucional/spr/conjunt ura/ANA_Conjuntura_Recursos_Hidricos_Brasil/A NA_Conjuntura_Recursos_Hidricos_Brasil_2013_Fi nal.pdf>.
ANA. Agência Nacional de Águas (2016). Planos de Recursos Hídricos. http://metadados.ana.gov.br/geonetwork/srv/pt/mai n.home?uuid=976eb381-2453-4664-9d318647210c5e76>.

AUSM. Associação dos Usuários da Água da Bacia Hidrográfica do Rio Santa Maria. (2015). Sistemas infraestruturais para uso das águas das barragens. Dom Pedrito, RS, Brasil, $<$ http//www.ausm.com.br/sistemasinfraestruturais $>$.

BARROS, F.G.N.; AMIN, M.M. (2008). Água: um bem econômico de valor para o Brasil e o mundo. Revista Brasileira de Gestão e Desenvolvimento Regional, $4 \quad$ (1): $\quad 75-108 .<$ http://www.rbgdr.net/012008/artigo4.pdf>.

BRASIL (1997). Lei № 9.433, de 8 de janeiro de 1997. Institui a Política Nacional de Recursos Hídricos, cria o Sistema Nacional de Gerenciamento de Recursos Hídricos, regulamenta o inciso XIX do art. 21 da Constituição Federal, e altera o art. $1^{\circ}$ da Lei $n^{\circ}$ 8.001, de 13 de março de 1990, que modificou a Lei no 7.990, de 28 de dezembro de 1989. Brasília, DF, Brasil,

$<$ https://www.planalto.gov.br/ccivil_03/leis/19433.ht $\mathrm{m}>$.

CARVALHO, C.M. (2012). Autogestão, Economia Solidária e Cooperativismo: uma análise da experiência política da Associação Nacional de Trabalhadores $e$ Empresas de Autogestão. Dissertação (Mestrado em Serviço Social) - Faculdade de Serviço Social da Universidade Federal de Juiz de Fora, Juiz de Fora, MG, Brasil.

CBHSM. Comitê de Gerenciamento da Bacia Hidrográfica do Rio Santa Maria (2014). Atas de reuniões. Rosário do Sul, RS, Brasil, $<$ http//www.comiteriosantamaria.com.br $>$.

CNRH. Conselho Nacional de Recursos Hídricos (2000). Resolução № 5, de 10 de abril de 2000. Brasília, DF,

Brasil, 
<http://www.cbh.gov.br/legislacao/20000410_CNRH Res005_DiretrizesCBH.pdf>.

CRH. Conselho de Recursos Hídricos do Rio Grande do Sul (2005). Resolução 15/2005. Porto Alegre, RS, Brasil, $<$ http://www.sema.rs.gov.br/upload/Resolu\%C3\%A 7\%C3\%A3o\%20CRH\%2015-2005.pdf>.

CRH. Conselho de Recursos Hídricos do Rio Grande do Sul (2007). Resolução 31/2007. Porto Alegre, RS, Brasil, $<$ http://www.sema.rs.gov.br/upload/Resolu\%C3\%A 7\%C3\%A3o\%20CRH\%2031-2007.pdf>.

CRH. Conselho de Recursos Hídricos do Rio Grande do Sul (2011). Resolução 96/2011. Porto Alegre, RS, Brasil, $<$ http://www.sema.rs.gov.br/upload/Resolu\%C3\%A 7\%C3\%A3o\%20CRH\%20n\%C2\%BA96\%20\%20estabelece $\% 20$ crit\%C3\%A9rios\%20para $\% 20$ a\%2 Oretirada\%20de\%20\%C3\%A1gua\%20para\%20irriga \%C3\%A7\%C3\%A3o\%20na\%20Bacia \%20do\%20Rio\% 20Santa\%20Maria.pdf>.

DAVIS, M.D. (2007). Integrated Water Resource Management and Water Sharing. J. Water Resour. Plann. Manage., 133(5): 427-445.

DULAC, V.F. (2013). Análise dos instrumentos de gestão dos recursos hídricos com ênfase nas ações do Comitê de Bacia do rio Santa Maria, RS Santa Maria, $R S$, Brasil. Dissertação (Mestrado em Engenharia Civil e Ambiental) - Centro de Tecnologia, Universidade Federal de Santa Maria, Santa Maria, RS, Brasil.

DULAC, V.F.; CRUZ, R.C. (2015). Mapeamento das Ações de Gestão dos Recursos Hídricos no Âmbito de um Comitê de Gerenciamento de Bacia Hidrográfica. Revista Brasileira de Recursos Hídricos, 20 (3): 583-593.

DRH. Departamento de Recursos Hídricos do Estado do Rio Grande do Sul (2008). Relatório Anual sobre a situação dos Recursos hídricos no Rio Grande do Sul. Porto Alegre, RS, Brasil, $<$ http//www.sema.rs.gov.br/>.

IBGE. Instituto Brasileiro e Geografia e Estatística (2010). Censo Demográfico 2010. Brasília, DF, Brasil, $<$ http://www.ibge.com.br>.

LLAMAS, M.R.; MARTINEZ-SANTOS, P. (2006). Significance of the Silent Revolution of intensive groundwater use in world water policy. In: ROGERS, P.P.; LLAMAS, M. R; MARTINEZCORTINA, L. (Org.). Water Crisis: Myth or Reality. Marcelino Botin Water Forum 2004. London: Taylor and Francis. p.163-180.

MACHADO, P.A.L. (2002). Recursos Hídricos, Direito Brasileiro e Internacional. Malheiros Editores.

PROFILL ENGENHARIA E AMBIENTE LTDA. Contratação de serviços de consultoria relativos ao processo de planejamento da Bacia Hidrográfica do Rio Santa Maria - Fases A, B e C. Processo Administrativo N. 012614-05.00/12-0. Relatório Técnico 1 - RT-1. Porto Alegre: SEMA/PROFILL, 2014. $70 \mathrm{p}$.

RIO GRANDE DO SUL (1995). Lei № 10.350, de 30 de dezembro de 1994 (publicada no DOE n. ${ }^{\circ}$, de $1^{\circ}$ de janeiro de 1995). Institui o Sistema Estadual de Recursos Hídricos, regulamentando o artigo 171 da Constituição do Estado do Rio Grande do Sul. Porto Alegre, RS, Brasil, < http://www.al.rs.gov.br/legis/m010/M0100099.ASP? Hid_Tipo=TEXTO\&Hid_TodasNormas $=12501 \&$ hTe xto=\&Hid_IDNorma=12501>.

SEMA. Secretaria de Estado do Meio Ambiente (2010). Histórico do Departamento de Recursos Hídricos. $<$

http://www.sema.rs.gov.br/upload/Historico_e_atri buicoes_DRH.pdf>.

TUCCI, C.E.M. (2008). Urban Waters. Estudos Avançados, 22 (63): $97 \quad$ - $112 . \quad<$ 
http://www.revistas.usp.br/eav/article/view/10295/1 $1944>$.

TUNDISI, J.G. (2006). Novas perspectivas para a gestão de recursos hídricos. Revista USP, 70: 24-35.

VIANA, N. (2008) Democracia e autogestão. Revista de Ciência Política, 37: 58-72, $<$ http://www.achegas.net/numero/37/nildo_37.pdf $>$. 